\title{
Anogenital squamous cell carcinoma in neglected patient
}

\author{
Svecova $\mathrm{D}^{1}$, Havrankova $\mathrm{M}^{2}$, Weismanova $\mathrm{E}^{3}$, Babal $\mathrm{P}^{4}$ \\ Department of Dermatovenereology, Faculty of Medicine, Comenius University, Bratislava, Slovakia. \\ danka.svecova@fmed.uniba.sk
}

\begin{abstract}
Skin squamous cell carcinomas (SCCs) are arguably the second most common carcinoma of the skin and are responsible for the majority of non-melanoma skin cancer deaths. Gynecologist treated a Caucasian 56-years old female patient for genital wart with podophyllotoxin cream. She did not achieve complete response and therefore she has interrupted the therapy and the collaboration with the gynecologist. At the time of evaluation the lesion had a size of man's palm in anogenital region and showed characteristic features of neoplasm. The regional lymph nodes have produced infiltrated painful bubo. PCR analysis for HPV proved negative. Histopathology revealed well-differentiated squamous cell keratinizing carcinoma from the tumor as well as from the regional lymph node packet. Staging computed tomography scans proved negative and pelvis scans disclosed regional lymphadenopathy underlying the tumor. Palliative radiation therapy (by linear accelerator) was administered for the oversized tumor to the total TD 50.0Gy. The patient died 6 months after diagnostic assessment from cardio-respiratory failure. Staging computed tomography before her death did not disclose distinct metastases in her inner organs. Well-differentiated squamous cell keratinizing carcinoma could be growing endophytically affecting the underlying adipose tissue and musculature, with spreading into the regional lymph nodes. The rate of metastases into inner organs seems to vary according to the aggressiveness and metastatic behavior of each SCC. The case report calls for attention to the importance of collaboration among various specialists assisting in the diagnosis and management of skin neoplasm (Fig. 5, Ref. 12). Full Text in PDF www.elis.sk. Key words: malignant epithelial neoplasm, squamous cell carcinoma, linear accelerator.
\end{abstract}

Non-melanoma skin cancer is the most common cancer in human and the squamous cell carcinoma (SCC) is arguably the second most common carcinoma of the skin. SCC is responsible for the majority of non-melanoma skin cancer deaths and the incidence of SCC depends on the selection of patients included into the study (1). The overall rate of metastases and local recurrence is, except in high-risk cases, less than $10 \%$ (2). Males are more frequently affected than females with the average age being approximately 70 years (3). About $90 \%$ of all SCC are located on UV-exposed sites of the body, especially on the head and face (4). The UV light is the most important etiologic factor (5). Of significance is the oncogenic potential of X-rays, arsenic, tar, and HPV infection (6). Immunosuppressed patients (e.g. transplant recipients) are in high risk of both, the carcinoma development and metastases spreading (7). Individuals suffering from genodermatoses, such as xeroderma pigmentosum, albinism, and epidermodysplasia verruciformis are at increased risk for SCC (8). We would like to draw further attention to this issue with a case of a neglected well-differentiated squamous cell keratinizing carcinoma.

${ }^{1}$ Department of Dermatovenereology, Faculty of Medicine, Comenius University, Bratislava, Slovakia, ${ }^{2}$ National Cancer Institute, Department of Dermatooncology, Bratislava, Slovakia, ${ }^{3}$ Oncological Institute of Saint Elisabeth, Bratislava, Slovakia, and ${ }^{4}$ Institute of Pathological Anatomy, Faculty of Medicine, Comenius University, Bratislava, Slovakia

Address for correspondence: D. Svecova, MD, PhD, Dpt of Dermatovenereology, Faculty of Medicine, Comenius University, Mickiewiczova 13, SK-813 69 Bratislava, Slovakia.

Phone: +421.2.57290498, Fax: +421.2.59357201

\section{Case report}

Gynecologist treated a Caucasian 56-year-old female patient for genital wart with podophylloxin cream of $0.5 \%$. The patient did not achieve a complete response after two treatment courses (twice daily for 3 days and further course was repeated after 7 days). The initial genital warty lesion was disvalued by the physician as well as by the patient. Therefore the patient has interrupted the therapy and collaboration with gynecologist. She has cured herself with disinfectant solutions containing iodine. Until the lesion has overgrown she was visiting her physician and then she was referred for evaluation to the Department of Dermatovenereology .

The examination revealed a cauliflower-like tumor localized in the region of left lower gluteal quadrant that was spreading closely to the anus and labia majora. The lesion was of $18 \times 15 \mathrm{~cm}$ at the base exceeding $1.5 \mathrm{~cm}$ in depth and it had the characteristic features of neoplasm, such as infiltration, unregulated elevated edge, and ulcerated surface, with brightly red unregulated basis with necrosis. The basis was irregularly coated with yellow pus. The surroundings of the tumor were slightly inflamed as well as the close intergluteal space (Fig. 1). The regional lymphadenopathy in the left groin formed a painful bubo having approximately $6 \times 5 \mathrm{~cm}$ in size. It was covered with not moving skin in relation to the underlying tissues. The skin color was without inflammatory features.

Additional investigations were performed to observe systemic involvement, including routine blood tests, urine analysis, biochemistry, electrophoresis, with no alteration except the C-reactive protein $(41.4 \mathrm{mg} / \mathrm{L}$, normal range $0-5 \mathrm{mg} / \mathrm{L})$. Immunological exami- 


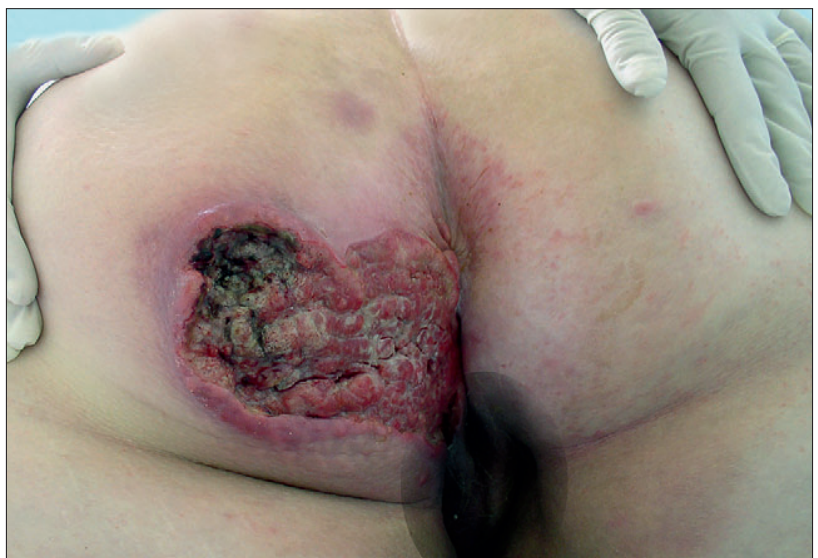

Fig. 1. Neglected squamous cell carcinoma localized in the ano-genital region. The tumor is localized in the upper gluteal quadrant spreading closely to the anus and major labia.

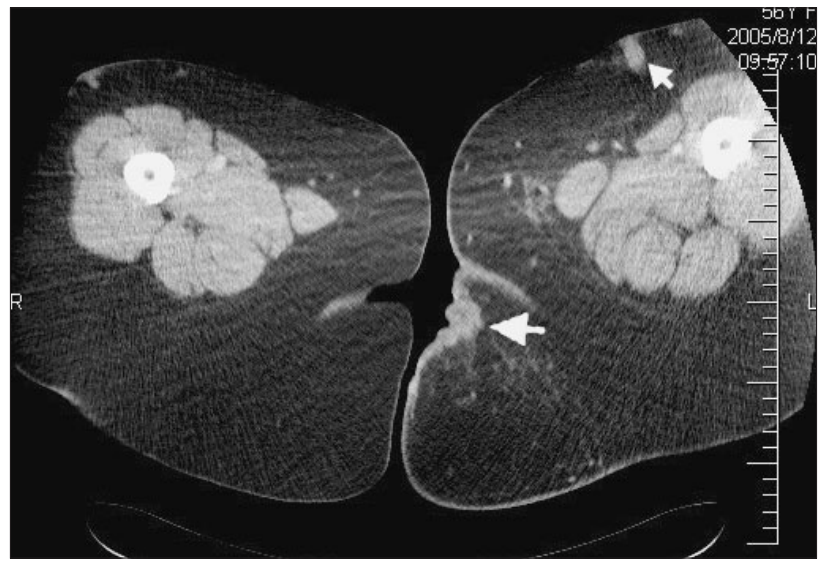

Fig. 2. CT scan revealed skin ulceration in the left gluteal region, with edematous border (large arrow-head). The hypodense formation on opposite side is thrombosed vein (small arrow-head).

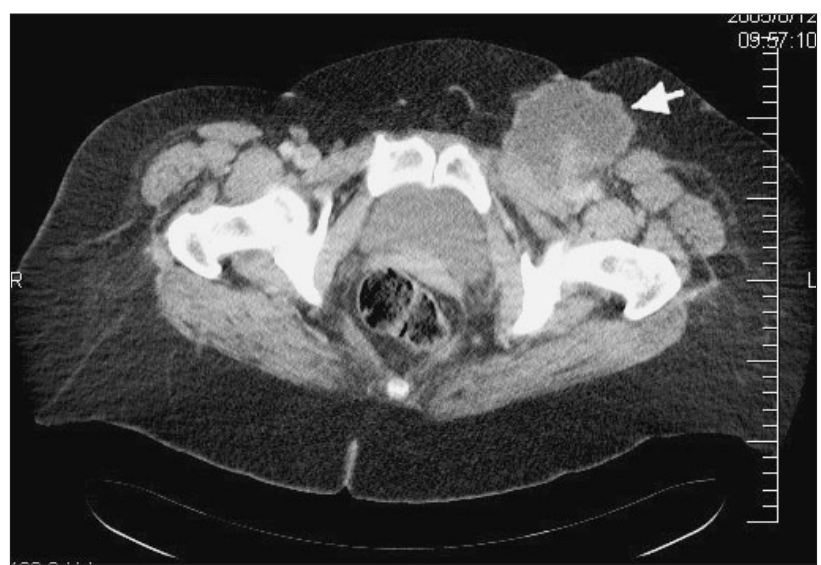

Fig. 3. CT scan showed necrotic enlarged packing of lymph nodes in the left groin (arrow-head).

nation did not disclose disturbance in characteristics of innate and acquired immunity. The chest X-ray, rectoscopy and colonoscopy, and gynecological examination proved negative. Staging - computed tomography scans of the chest, abdomen proved negative.

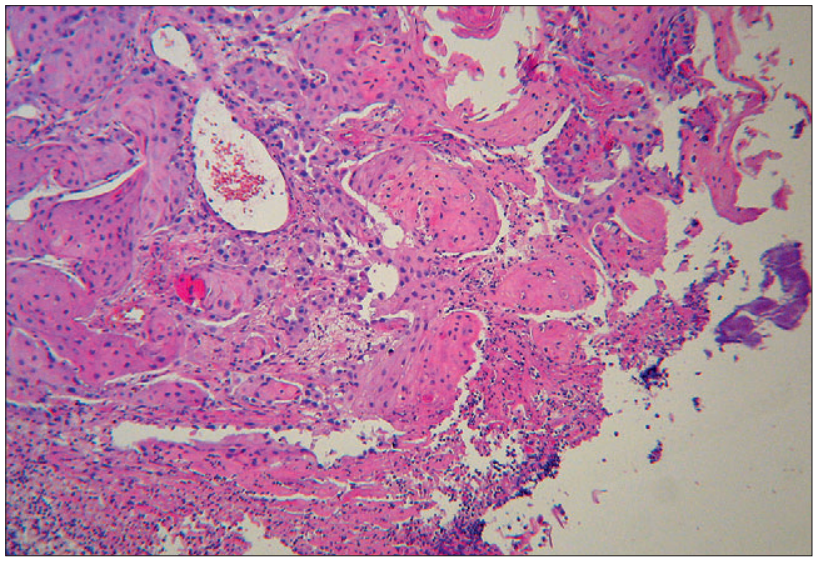

Fig. 4. Squamous cell carcinoma formed by well-differentiated squamous cells with keratinization (Hematoxyllin and eosin, $\mathbf{x 1 0 0 )}$ ).

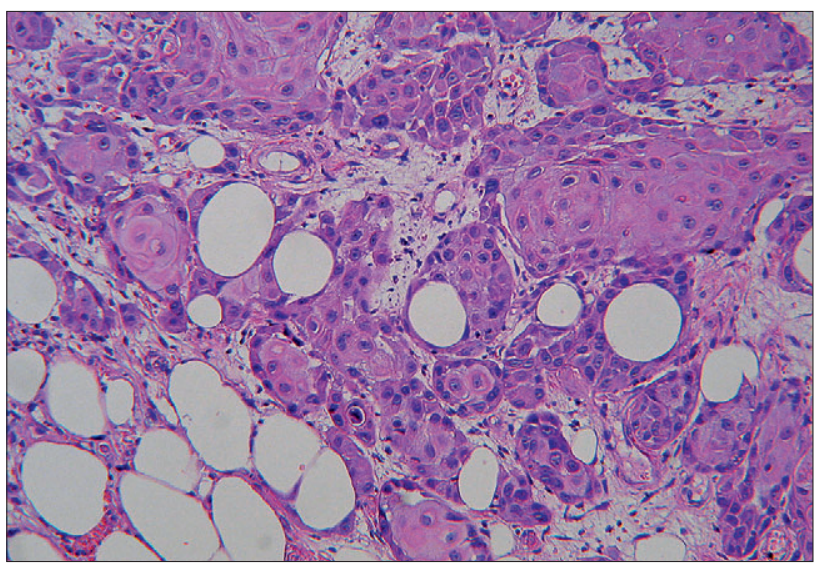

Fig. 5. Squamous cell carcinoma infiltrates adipose tissue (Hematoxyllin and eosin, x250).

Bone marrow aspiration specimen did not disclose abundant cellularity and infiltration of atypical cells. CT scan of the pelvis did not discover attack of inner organs and revealed defect of the skin at the side of the left gluteal region with an edematous border (Fig. 2). CT scan of the medial side of the left thigh and left groin showed hypodense formation $(8.47 \times 6.68 \mathrm{~cm})$, which was revealed as a packing of lymph nodes (Fig. 3). The staging was evaluated as T4N1M0.

Histopathological findings revealed the tumor tissue that was formed by nest of squamous cells infiltrating adipose tissue. The tumor cells formed foci of keratinization. The cells had typically abundant eosinophilic cytoplasm and vesicular nuclei with prominent nucleolus without major atypia. The stroma was edematous. There was superficial exulceration with leukocytes infiltration. Histopathological analysis revealed well-differentiated squamous cell keratinizing carcinoma (Figs 4 and 5). The cells with the same characteristics were disclosed also in the biopsy specimen from the regional lymph node in the left groin.

PCR detection for HPV DNA was extracted from the $10 \mu \mathrm{m}$ sections in the formalin-fixed paraffin embedded tumor tissue. The presence of high risk HPV DNA was determined by nested PCR amplification using degenerated primers MY09/MY11 and GP5+/ 
GE6 + and by agarose gel electrophoresis. The integrity of extracted DNA was determined by GAPDH PCR amplification. The HPV specific DNA was not detected in any of the examined patient samples.

The surgical excision was not recommended due to the tumor oversize. The palliative radiation therapy was administered to the region affected by the tumor, two opposing fields, energy of $18 \mathrm{MVX}$ fractionally, dose per fraction 2 Gy to dose of $40 \mathrm{~Gy}$, continuing with restricted field to total dose of 50.0 Gy. The linear accelerator (LINAC 2100) was used. The therapy flattened the tumor and the patient has developed skin post actinic reaction G1 (dry desquamation) that was treated topically with betamethasone ointment.

The patient developed algesic syndrome and suddenly died of cardio-respiratory failure six months after diagnosis assessment. At the time of death the patient suffered from bronchopneumonia, urinary infect and cachexia. Despite the oversize of the tumor and regional lymphadenopathy, the patient did not show distinct metastasis affecting the inner organs as it has been documented by the computed tomography scans. Necropsy was not done because the family disagreed.

\section{Discussion}

SCC of the skin represents malignant epithelial neoplasm with ability to focal infiltration and tissue destruction. Furthermore, SCC could originate from pre-existing skin lesions such as old burn scars, leg ulcers, lupus vulgaris, and other chronic inflammatory disorders or de novo on unaffected skin.

In the genital and on the ano-genital region various types of SCC ccan be localized. The verrucous carcinoma (VC) is considered on the basis of studies of aggressiveness and metastatic behavior of each SCC variant, to be a distinct low-grade variant of SCC ( $\leq 2 \%$ risk of metastasis) (1). VC obviously has warty, fungating, often cauliflower-like appearance and is up to $50 \%$ associated with HPV type $6,11,16$, or 18 (6). All VCs share very similar histopathological features with typical HPV cytopathologic changes. VC takes rarely an aggressive course. VCs may lead to local compression and local destruction of adjacent structures.

In addition, de novo SCC occur primarily in Caucasian patients either on sun damaged or also on sun-protected skin. There is approximately $8-14 \%$ incidence of regional or distant metastases with de novo SCCs (9). According to the classification of cutaneous SCC in risk-based categories, SCC de novo has high malignant potential (>10\% risk) (10). De novo SCC has multiple cell atypia in histological finding and aggressive growth with high suspension of distinct metastases.

Besides, the common invasive SCCs and SCCs with horn formation could be situated anywhere including ano-genital region. It is primarily spreading endophytically as subcutaneous nodule or ulceration.

In our patient the histopathological analysis revealed welldifferentiated squamous cell keratinizing carcinoma. PCR analysis did not disclose HPV virus origin. Because of neglected care the tumor was growing endophytically affecting the underlying adipose tissue and later the musculature.

For any given lesion, the metastatic potential of SCC is related to factors, such as size and depth of invasion and also to histological grade of differentiation, as well as perineural invasion (11).
Despite the generally good prognosis of cutaneous SCC, the behaviour of metastatic SCC is very poor, with less than $35 \%$ of patients surviving 5 years (12).

\section{Conclusions}

Neglected well-differentiated squamous cell keratinizing carcinoma may grow endophytically affecting the underlying adipose tissue and musculature, with spreading into the regional lymph node. The rate of metastases into inner organs seems to be various according to the aggressiveness and metastatic behavior of each $\mathrm{SCC}$ variant. The case report calls for attention to the importance of collaboration among various specialists assisting with the diagnosis and management of skin neoplasm.

\section{References}

1. Cassarino DS, Derienzo DP, Barr RJ. Cutaneous squamous cell carcinoma: a comprehensive clinicopathologic classification. Part one. J Cutan Pathol 2006; 33 (3): 191-206.

2. Joseph MG, Zulueta WP, Kennedy PJ. Squamous cell carcinoma of the skin of the trunk and limbs: the incidence of metastases and their outcome. Aust N Z J Surg 1992; 62 (9): 697-701.

3. Katz MH. Nonmelanoma skin cancer. Md Med J 1997; 46 (5): 239-242.

4. Dinehart SM, Nelson-Adesokan P, Cockerell C, Russell S, Brown R. Metastatic cutaneous squamous cell carcinoma derived from actinic keratosis. Cancer 1997; 79 (5): 920-923.

5. Barksdale SK, O'Connor N, Barnhill R. Prognostic factors for cutaneous squamous cell and basal cell carcinoma. Determinants of risk of recurrence, metastasis, and development of subsequent skin cancers. Surg Oncol Clin N Am 1997; 6 (3): 625-638.

6. Bezerra AL, Lopes A, Landman G, Alencar GN, Torloni H, Villa LL. Clinicopathologic features and human papillomavirus DNA prevalence of warty and squamous cell carcinoma of the penis. Am J Surg Pathol 2001; 25 (5): 673-678.

7. Kuijken I, Bouwes Bavinck JN. Skin cancer risk associated with immunosuppressive therapy in organ transplant recipients: epidemiology and proposed mechanisms. BioDrugs 2000; 14 (5): 319-329.

8. de Oliveira WR, Festa Neto C, Rady PL, Tyring SK. Clinical aspects of epidermodysplasia verruciformis. J Eur Acad Dermatol Venereol 2003; 17 (4): 394-398.

9. Cassarino DS, Derienzo DP, Barr RJ. Cutaneous squamous cell carcinoma: a comprehensive clinicopathologic classification. Part two. J Cutan Pathol 2006; 33 (4): 261-279.

10. Petter G, Haustein UF. Histologic subtyping and malignancy assessment of cutaneous squamous cell carcinoma. Dermatol Surg 2000; 26 (6): 521-530.

11. Fernandez-Flores A. CD30+ cells in regressing keratoacanthoma and inn non-keratoacanthomatous squamous cell carcinoma. Bratisl lek Listy 2008; 109 (11): 508-512.

12. Rowe DE, Carroll RJ, Day CL Jr. Prognostic factors for local recurrence, metastasis, and survival rates in squamous cell carcinoma of the skin, ear, and lip. Implications for treatment modality selection. J Am Acad Dermatol 1992; 26 (6): 976-990. Accepted January 13, 2012. 